\title{
SMART UBIQUITOUS LEARNING ENVIRONMENTS
}

\author{
Matthew Montebello \\ University of Illinois, USA
}

\begin{abstract}
The concept of ubiquitous computing is notoriously documented and successfully applied as society at large has blissfully accepted and heavily relies upon the pervasive and omnipresence of the online network to wirelessly connect and seamlessly access the massive knowledge-base and social media. On the other hand, smart environments are a complex research area that require meticulous attention and in-depth investigation before being employed as they interact directly with the users. When both these areas come together within an educational environment, the necessity and exigency of ensuring safe and sound conditions escalate even more. In this paper, we present ubiquitous learning as one of a number of elearning affordances within a new learning model as it factors in to addresses one particular aspect of a smart classroom. The justifications, challenges, and recommendations of embodying our philosophical concept within a working model are also put forward in what could potentially be the next generation model of physical classrooms.
\end{abstract}

\section{KEYWORDS}

Ambient Intelligence, e-Learning, Ubiquitous Computing.

\section{INTRODUCTION}

The use of technology to assist people in either their challenges or to enhance their quality of life is best witnessed in the deployment of smart or ambient intelligent environments. These environments do not just incorporate a number of different technologies within a finite space, but bring together a combination of issues that render the whole implementation process far from straightforward or simple. The matter becomes even more complicated as we deal with people's education and the repercussions that the employment of such environments might have on their lives. Additionally, the academic aspect introduces further elements into the scenario that further renders the already challenging investigation problematic and intricate, reducing further the chances of getting it right. In this paper, we apply the ubiquitous learning affordance to smart environments in an attempt to demystify and deconstruct the multifarious nature of such a research domain. Ubiquitous learning refers to the possibility of a person being involved within a learning situation which is not bound by time or space[1]. The anytime, anywhere cliché, as it is commonly referred to, summarises the mobile commodity that portable computing devices made possible, but also the effortless and seamless capabilities of wirelessly connecting and accessing the online network that hosts the World-Wide Web. Such an opportunistic liberty and prospective functionality to access information and e-learning courses has also contributed in reducing the continuum between formal education and informal learning[2]. Our model incorporates additional learning affordances that all factor in and contribute to the educational aspect of smart learning environments, but in order to correctly and meticulously investigate such a complex environment, every individual influencing feature has to be inspected and studied in isolation. We further argue that the educational aspect is just one side of the multi-faceted smart classroom, and that there is

DOI : $10.5121 /$ ije. 2017.5402 
further scope and research to probe into the other dimensional aspects. The conceptual philosophical reasoning behind the different aspects of smart learning environment together with the granular elements that feature within each aspect have been realistically harnessed within a research project to investigate both the rationale of our models, and the effectiveness of a smart ubiquitous learning environment.

The rest of the paper is organized as follows. In the next section, further details regarding the different e-learning affordances that contribute to the educational aspect of smart learning environments are given, with particular focus to the ubiquitous learning affordance. In Section 3 we pursue the investigation into smart learning environments as we segregate its different dimensional aspects to categorically focus our efforts on specific aspects. The educational dimension will be at the centre of our attention, with particular emphasis on the ubiquitous learning factor covered in the previous section. Section 4 presents the planned empirical study that brings together the previous two sections as this research reaches its high point to test our philosophical models and confirm our epistemological stance regarding smart learning environments. Recommendations, next steps to follow and final conclusions close the paper in the last section.

\section{E-LEARNING AFFORDANCES}

As e-learning evolved and gained popularity, web technologies evolved at even a faster rate pushing the boundaries and expanding the possibilities for e-learning to offer additional functionalities and richer capabilities. Such evolutions in web technologies and e-learning systems enabled additional affordances as Kalantz is and Cope[3] copiously explain as they present their seven principles, shown in Figure 1, whereby these new e-learning affordances have been instrumental in transforming and shifting the pedagogical paradigm from didactic to reflexive.

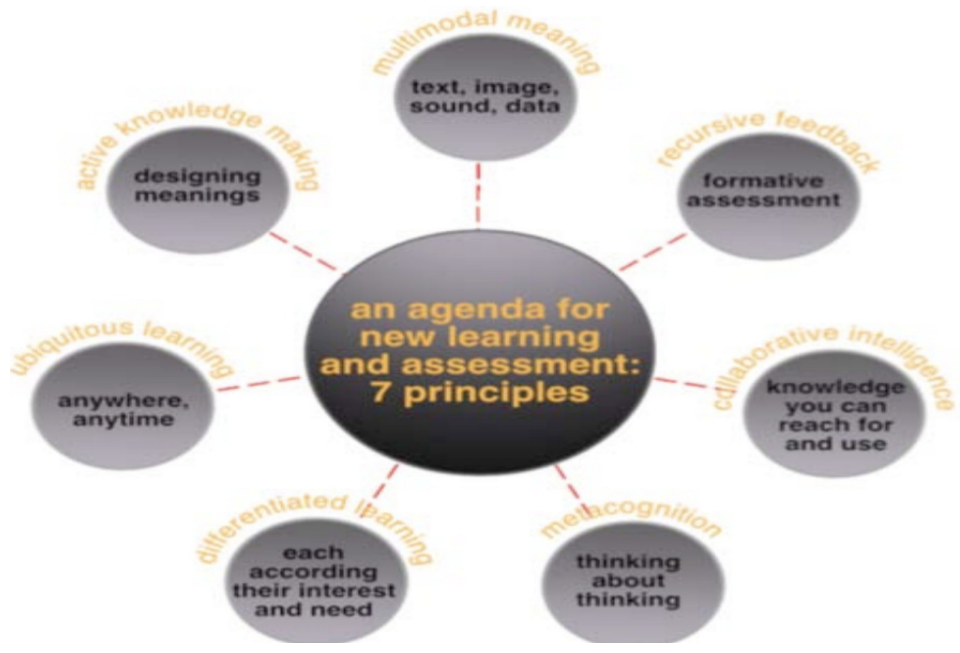

Figure 1: e-Learning Affordances [3]

The first e-learning affordance to be reviewed in some detail is the ubiquitous learning, as it is of special interest to this paper. As mentioned in the introduction the main concept behind this affordance is the fact that education is not limited to a specific time and place, thereby opening up the spatio-temporal dimension of e-learning. The implications for education are numerous and worth investigating as they shed important light on the concept of a smart learning environment. The ubiquity fact is most notorious within educational realms for the no physical boundaries and the new discovered mobility that learners possess, however within a smart classroom concept 
such an affordance is diminished due to the confinement of an ambient intelligent space. This does not mean that learners are constrained to stay within a classroom but within the finite space of where the ambient environment is being applied. This could well be a class, but could also be an entire building or even a city. As long as the learners are within the limits of the ambient intelligent space, then the ubiquitous affordance of anywhere within that space applies. On the other hand, the luxury of no time delimitations fully applies to a smart environment and thereby learners who conveniently have access round the clock within the smart learning environment can take full advantage. This will of course enhance the flexibility and add-value to the learning process as students can self-pace themselves and optimise the time according to their personal learning patterns. The availability of information as well as instantaneous access to educational resources also impinges on the relationship that exists between the teacher and students. This does not mean that there will be no relationship, but simply that the relationship will be different from what we are used to. Such a diverse way of accessing knowledge, previously the realm of the educator, requires further investigation and consideration. Some of the critics of such an affordance[4] argue that the omnipresence and availability of online access will further increase the digital divide between skilled and unskilled users, as well as between rich and poor communities. Additionally, other negative implications are identified, namely, burden from permanent work connection, as well as disorientation from information overload. However, from an education point of view students could potentially use their continuous connection to access information during formal assessment, while creating stressful situation even in class when the network is down. Others[5] argue that student who have online access throughout the day tend to develop bad studying habits as they tend to move their attention away from the class. In order to control such an unpleasant effect on education access to online information still needs to be controlled, and like all other educational resources, students need to appreciate and understand when to use the resource when the appropriate need arises. Such a trade-off between the benefits and disadvantages of ubiquitous learning is typical of any tool and all other affordances, placing the onus on the educator and the student to wisely and beneficially make good use of it at the most appropriate time.

Another affordance in this new learning model is related to active knowledge making whereby the learner's role is transformed from that of a knowledge consumer who passively acquires and memorizes information through formal didactic education, to a much active role of producing, authoring and developing content while discovering, discerning, and curating educational material that occurs available online. From a discursive point of view multi-modal meaning is another e-learning affordance that witnesses a transformation from the classical literacies of textbooks, assignments and summative tests, to a variety of media in numerous modes and knowledge representation. The transformation of the summative evaluative method to a formative one can be seen in the recursive feedback affordance. In this case the retrospective judgmental assessment has no educational benefits in contrast to a constructively prospective one that is formed along the process. Additionally, the use of learning analytics can dynamically assist educators and academically help learners. The collaborative intelligence affordance exposes the benefits of the social dimension that portrays the lone learner that focusses on individual cognition and memory, to a communal peer-to-peer scenario. This affordance is reinforced with the appropriate use of Web 2.0 knowledge tools that source a resourceful social memory. From a cognitive point of view a transformation from a learner that is required to focus on factual information in an attempt to memorise facts and apply theories, to a critical learner. This metacognition affordance enables self-reflection and a realistic knowledge application that requires the learner to think about thinking and practices through reasoning rather than rote. Finally, the affordance of differentiated learning enables the personalisation of educational content and processes from a homogenised standard curriculum that all learners have to follow, to a fitting customised alternative. Such a flexible possibility supports the notion of adaptation of 
content, assessment and learning as each learner is individually catered for depending on the individual needs, interests and educational requirements.

These seven affordances are viewed as enabling qualifiers that web technologies, particularly Web 2.0, made possible, transforming the pedagogic approach from a didactic to a reflexive one[3]. Most notorious technologies that enabled such a shift include learning management systems; e-textbooks; flipped classrooms; intelligent tutors, games and simulations; synchronous discussion boards; Web workspaces and e-portfolios; adaptive, personalised and differentiated instruction; and automated machine assessment. The authors argue that technology is pedagogically neutral, and that the real game-changer is the pedagogy rather than the technology. We follow this same philosophy as we investigate the pedagogical reasoning of our smart learning environment rather than the technological elements or instruments involved.

\section{SMART LEARNING ENVIRONMENTS}

As we focus on the pedagogical practices of our smart learning environment, we direct our attention towards the ubiquitous learning affordance. We do so following a thorough analysis of the research area especially taking into consideration the limited but focussed literature. We employ our philosophical reasoning regarding smart learning environments to review the available literature to gauge the different motivational reasons that the various researchers employed. We believe that smart learning environment have a number of aspects that define them, and thereby requires an elaborate study to set apart the different aspects and investigate each individual dimensional aspect is isolation. The three aspects upon which we based our work and through which we reviewed previous research are the technological, educational and social aspects. Each of these dimensional aspects are further broken down into finer elements to facilitate and divide the intricate issues down to convenient and manageable granularity.

A number of studies[6][7][8] focussed solely on the technological aspects to perform numerous investigations as a variety of physical equipment was employed in their research. The use of sensors to control the room temperature while cameras, projectors and big screens litter the classroom to create a technologically-heavy environment. Some other researchers[9][10][11] focussed solely on specific equipment as they developed high-tech desks and virtual students projections to create a fully ambient classroom around the educator. Wireless technologies also fall part of the technological aspect that were the attention of other research projects[12][13] as RFID (Radio Frequency ID) and NFC (Near Field Communication) media were extensively employed to perform individual identification of learners and educators in an attempt to tailor the services, as well as perform additional functionalities. Very few research projects [14][15] considered the educational aspect as learner profiles and content management issues are considered, while none of the projects reviewed in the literature focussed on the social dimension. The technological, educational and social aspects all require due attention if a proper investigation is to be performed whereby a complete and realistic attempt of a smart learning environment is to be developed. One of the most important aspects is the social dimension that has not been properly investigated in relation to smart learning environments. In our model, we refer to this aspect due to the importance and manifestation of numerous social characteristics that occur within the classroom itself. Amongst these are multidimensionality, simultaneity, immediacy, unpredictability, publicness and history, which in one way or another distinguish our research from any other smart learning environment research. The technological aspect is very much represented as discussed above, however we still consider this aspect as an important dimension due to its strong influence in smart environments. To such extremes we follow Ducatel et al., [16] by following the five technological qualities proposed, namely, unobtrusive hardware, seamless/wireless communication infrastructure, intuitive/friendly user interface, safe/trusting reassurance for learners, and dynamic/distributed device network. Finally, the third aspect is the 
educational dimension that follows the e-learning affordances discussed in Section 2, one of which is the ubiquitous learning concept. All these issues will now be presented within the empirical study being planned to test and investigate further the proposed ubiquitous smart learning environment.

\section{EMPIRICAL STUDY}

The empirical study will involve the combination of all three aspects as higher education students will be experiencing while attending class in the first quarter of 2018. The educational aspect, that incorporates the e-learning affordances, will be represented through the Scholar platform (Figure 2 ) which has been purposely developed to embody these same affordances[17].

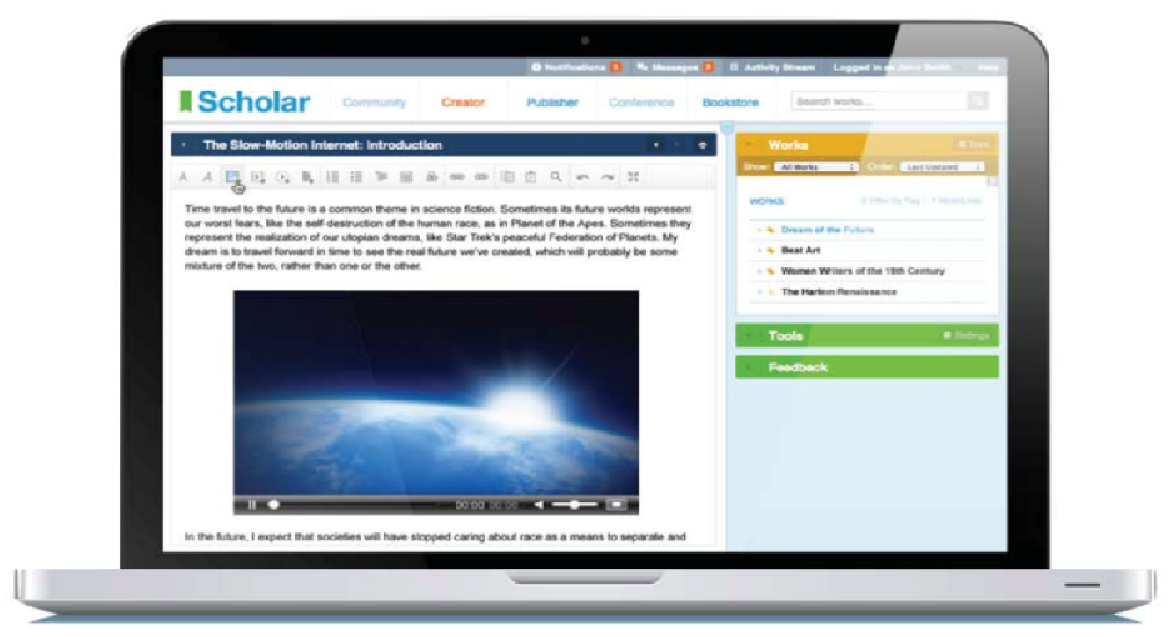

Figure 2 - The Scholar platform [3]

Participants will be enrolled to the environment to follow their academic course while experiencing different functionalities that reflect the different affordances. The ubiquitous learning affordance is explicitly manifested in the fact that Scholar is a web-based platform accessible from anywhere over a Web browser at any time of the day. Time stamping and logs of users logging in together with a full trace of their activities while using the platform is saved and available for data analysis. Every course has a dedicated community with its specific activity stream that keeps track of all that is happening within that community, as well as, updates, recent activities, and publications that the other members within the same community have shared. Students will be required to have a Scholar account and log onto the platform to access the specific course community to which they would have been enrolled. Irrespective whether the students will be joining the course session within the physical classroom or from an alternate place like home, they still need to be logged in over Scholar and their presence recorded.

The technological aspect of the study is represented through the different devices being employed within a high-tech classroom that provides an ideal infrastructure for fine-grained research using numerous technologies. This lab enables the capture of learner interactions with digital technologies in real-time, as the collection and storage of massive and varied data is possible. Cameras within the classroom, as well as cameras on learners' computers, if remotely connected, will be employed to project the person who will be speaking or making an intervention over the big screen within the classroom. This screen is also projected on the shared online environment that enables a collaborative learning amongst those within the classroom and those connected from a remote location. 
Finally, the social aspect is achieved through the physical presence of students and teacher within the physical classroom together with the students who are remotely connected, as they all will be virtually represented over the same shared collaborative learning platform. In this way all the students and the teacher, irrespective wherever they may be located, as long as they are logged into the platform and collaborative environment, they form part of the class. Once the session commences, the collaborative environments acts as a social forum for all participants to feel part of the class by sharing a common chat, potential to have private chat with a single or group of participants, a shared common whiteboard, as well as a shared common display screen to present one's own work or any other content. Additionally, similar to any social scenario, when a student or a teacher within the physical classroom starts to talk, sound-sensitive receptive cameras focus on that person and project the image on the communal screen within the collaborative environment. If on the other hand a remote student requests permission to talk and enables the functionality to address everyone, the personal camera on the remote computer will similarly project the image of that student on the communal screen. If a remote student decides to use a saved image, a graphic or an avatar instead of a real image, then this is also possible.

All the data collected will be analysed to perform a series of learning analytics together with an analysis of interactions, interventions, and other statistical analysis. Additionally, a pre and post survey will be administered to gauge the participants thoughts and opinions. A number of data capturing techniques will also be employed through the Scholar platform as the analytics section enables numerous functionalities related to the educational use of the same platform. Finally, additional logistical data is collected over the course of the entire semester to shed light on the social aspects of the virtual classroom in collaboration with the physical one. Attendance data, in person or virtual, can also shed some light on the research being performed.

\section{FUTURE WORK \& CONCLUSIONS}

Following the first wave of collected data, a full analysis of the initial setup will be employed to shed light on the proposed architectural setup, especially the intermediate learner feedback given during the actual running of the empirical study. Additionally, the focus groups and closing comments collected from the final survey will be instrumental in identifying problem areas or specific issue related to any particular aspect of the smart learning environment. This will lead to the further tweaking of the environment, as well as any major changes or additions that might be required, before permanently establishing the educational environment for the next academic year, preparing for a full year of continuous user testing.

In this paper, we have presented the three main important standpoints of our research related to ubiquitous smart learning environments. Initially the concept of smart environments was applied and justified within an academic situation. However, we strongly argued that in order to effectively realise such a project in a correct and accurate way, three aspects are required to be thoroughly investigated and applied. The social aspect is imperative due to the communal presence of students and teacher within the classroom, physical or virtual. Secondly, the technological aspect is also very important due to the crucial role that various instruments play within a high-tech classroom as specific functionalities are required, as well as, data is needs to be collected. Finally, the educational aspect is central for obvious reasons. In this case we related this aspect to the use of seven e-learning affordances upon which the virtual learning environment is based upon. The combination of these three aspects, through their different representations, come together to offer a complete and ubiquitous smart classroom environment. The third standpoint presented is related to the empirical study where details of how this will be performed in reality were given, together with justified rationale behind our reasoning. The next steps include the full execution of the empirical study together with the collection of all the required data and eventual analysis and evaluation. Our recommendation to all researchers in this domain 
International Journal of Education (IJE) Vol.5, No.3/4, December 2017

is not to underestimate the complexity of smart classrooms, and to ensure to cater for all aspects that individually play a distinct and important role that eventually impinges on the final outcome of the students' educational achievement.

\section{REFERENCES}

[1] M. Twindale, "From Ubiquitous Computing to Ubiquitous Learning," in Ubiquitous Learning, Champaign, Illinois, University of Illinois, 2009.

[2] S. Yahya, E. Ahmad and K. Abd Jalil, "The definition and characteristics of ubiquitous learning: A discussion," International Journal of Education and Development using Information and Communication Technology (IJEDICT), vol. 6, no. 1, pp. 117-127, 2010.

[3] B. Cope and M. Kalantzis, e-Learning Ecologies, New York: Routledge, 2017.

[4] E. N. Asiimwe and S. Z. Khan, "Ubiquitous Computing in Education: A SWOT Analysis by Students and Teachers," in 12th World Conference on Mobile and Contextual Learning (mLearn 2013), Qatar, 2013.

[5] S.-W. Hsieh, Y.-R. Jang, G.-J. Hwang and N.-S. Chen, "Effects of teaching and learning styles on students' reflection levels for ubiquitous learning," Computers \&Education, vol. 57, no. 1, pp. 11941201, 2011.

[6] L. Winer and J. Cooperstock, "The "Intelligent Classroom": changing teaching and learning with an evolving technological environment," Computers \& Education, vol.38, pp. 253-266, 2002.

[7] R. Ramadan, H. Hagras, M. Nawito, A. Faham and B. Eldesouky, "The Intelligent Classroom: Towards an Educational Ambient Intelligence Testbed," in 6th International Conference on Intelligent Enviroments, 2010.

[8] P. Santana-Mancilla, M. Echeverrie, J. Santos, J. Castellanos and A. Diaz, "Towards Smart Education: Ambient Intelligence in the Mexican Classrooms," Social and Behaviousal Sciences, vol. 106, pp. 3141-3148, 2013.

[9] Y. Shi, W. Xie, G. Xu, R. Shi, E. Chen, Y. Mao and F. Liu, "The Smart Classroom: Merging Technologies for Seamless Tele-Education,” Pervasive Computing, vol. 2, no. 2, pp. 47-55, 2003.

[10] M. Antona, G. Margetis, S. Ntoa, A. Leonidis, M. Korozi, G. Paparoulis and C. Stephanidis, "Ambient Intelligence in the Classroom: an Augmented School Desk," in 3rd International Conference on Applied Human Factors and Ergonomics, Miami, 2010.

[11] T. Tagawa, N. Fujimura, S. Hasikura and H. Inoue, "Introduction and management of inter- campus learning assistant system for distributed campus," in 37th annual ACM SIGUCCS fall conference, New York, 2009.

[12] C. Shen, Y. Wu and T. Lee, "Developing a NFC-equipped smart classroom: Effects on attitudes toward computer science," Computers in Human Behavior, vol. 30, pp.731-738, 2014.

[13] R. Ramadan, "Leveraging RFID Technology for Intelligent Classroom," in 4th International Design and Test Workshop, 2009.

[14] A. Leonidis, G. Margetis, M. Antona and C. Stephanidis, "ClassMATE: Enabling Ambient Intelligence in the Classroom," International Journal of Computer, Electrical, Automation, Control and Information Engineering, vol. 4, no. 6, pp. 1058-1061, 2010. 
International Journal of Education (IJE) Vol.5, No.3/4, December 2017

[15] G. Margetis, A. Leonidis, M. Antona and C. Stephanidis, "Towards Ambient Intelligence in the Classroom," in Universal Access in HCI, vol. 4, Berlin Heidelberg, Springer-Verlag, 2011, pp. $577-$ 586.

[16] K. Ducatel, M. Bogdanowicz, F. Scapolo, J. Leijten and J.-C. Burgelman, "Scenarios for Ambient Intelligence in 2010," Cordis, Seville, 2001.

[17] B. Cope and M. Kalantzis, "Towards a new learning : the Scholar social knowledge workspace, in theory and practice," E-Learning and Digital Media, vol. 10, no. 4,pp. 332-356, 2013.

\section{AUTHORS}

Matthew Montebello is an associate professor at the Department of Artificial Intelligence at the Faculty of ICT, University of Malta. He heads the Agent Technology Research Group at departmental level, as well as coordinates a number of Interest Groups within the same faculty. Before joining the University in 1999 with a PhD in Computer Science he was already heavily involved in Education in secondary schools after graduating in 1990 at the University of Malta B.Ed.(Hons) degree. Having obtained an extensive teaching experience and having been involved with the introduction of computer labs through the Ministry of Education, he proceeded to follow the Computer Science domain when he pursued his post-graduate studies obtaining a Masters and a Doctorate at the Cardiff University in Wales in 1996 and 1998 respectively. Furthermore in 2009 and 2016 he also completed an M.A. and an Ed.D. (Higher Education) specialising in the application of artificial intelligence to e-learning. 